\title{
Rare Earth Doped Alkali Earth Sulfide Phosphors for White-Light LEDs
}

\author{
K. Suresh, ${ }^{1}$ K. V. R. Murthy, ${ }^{2}$ Ch. Atchyutha Rao, ${ }^{3}$ and N. V. Poornachandra Rao ${ }^{4}$ \\ ${ }^{1}$ Department of Physics, CSR Sarma College, Ongole 523 001, India \\ ${ }^{2}$ Department of Applied Physics, Faculty of Engineering and Technology, MS University of Baroda, Vadodara 390 001, India \\ ${ }^{3}$ Department of Physics, VRS \& YRN College, Chirala 523 157, India \\ ${ }^{4}$ Department of Physics, VSR \& NVR College, Tenali 522 201, India
}

Correspondence should be addressed to K. Suresh, sureshkukkamalla@gmail.com

Received 26 November 2011; Accepted 25 December 2011

Academic Editors: G. Astakhov and V. Kochereshko

Copyright $\odot 2011 \mathrm{~K}$. Suresh et al. This is an open access article distributed under the Creative Commons Attribution License, which permits unrestricted use, distribution, and reproduction in any medium, provided the original work is properly cited.

CaS:Eu and SrS:Eu phosphors were synthesized by solid-state reaction. The effects of doping concentrations on luminescent properties of phosphors are investigated. The samples are excited using electroluminescent blue light emitting diode (460 nm) to examine them as potential coating phosphors for white-light LEDs. The excitation and emission spectra of these phosphors are broadband which can be viewed as the typical emission of $\mathrm{Eu}^{2+}$ ascribed to the $4 \mathrm{f}-5 \mathrm{~d}$ transitions. Because of their broadband absorption in the region $400-630 \mathrm{~nm}$, these phosphors meet the application requirements for blue LED chips. A white-light LED was fabricated through the integration of a $460 \mathrm{~nm}$ chip. The results indicate that these phosphors can be considered as candidates for the application in blue LED chip-based white-light LEDs.

\section{Introduction}

There has been much interest in light emitting diodes (LEDs) with emission wavelengths in the ultraviolet-to-infrared range. Major developments in wide bandgap III-V nitride compound semiconductors have led to the commercial production of high-efficiency LEDs [1-4]. Traditional colored LEDs have proven effective in signal applications, as indicator lights, and in automotive lightning. The development of white LEDs as a cost-competitive, energy-efficient alternative to conventional electrical lightning is very important for expanding LED applications toward general white lightning [5-7]. Phosphors activated with rare earth metal have been widely investigated in the past few decades on account of their technological importance [8]. In particular, phosphors for LED applications have received significant attention in recent years with the rapid development of white LEDs, which have such merits as high efficiency, long lifetime, and low power consumption [9]. Alkali earth sulfide phosphors, such CaS: $\mathrm{Eu}^{2+}$ (red) and $\mathrm{SrS}: \mathrm{Eu}^{2+}$ (orange) are also good candidates for LED applications because all of them have strong absorption in the blue region that is suitable to blue
LED pumping. Sulfide phosphors have been ignored for a long time because they are not chemically stable. However, sulfide phosphors fit well for LED applications with adhesive seal and blue excitation.

In the present study, we therefore investigated the optical properties of $\mathrm{Eu}^{2+}$ doped alkali earth sulfides, with particular focus on the photoluminescence (PL) characteristics of these phosphors and the color variations of phosphor-converted colored LEDs pumped by blue LEDs.

\section{Experimental}

SrS:Eu and CaS:Eu powdered samples have been prepared using a solid-state reaction method. Raw materials of assay 99.9\% $\mathrm{SrCO}_{3}$ and $\mathrm{CaCO}_{3}$ are mixed with sulfur in a $3: 2 \mathrm{wt}$. ratio. Dopant compound $\mathrm{Eu}_{2} \mathrm{O}_{3}$ was added with a specified doping concentration for each sample. Ammonium fluoride $\mathrm{NH}_{4} \mathrm{~F}$ was used as flux. The samples are weighed, mixed, and then ground into fine powder using agate mortar and pestle about an hour and then heated to $950^{\circ} \mathrm{C}$ and kept for $2 \mathrm{~h}$ in reducing environment. Body colors are orange and red for $\mathrm{SrS}: \mathrm{Eu}^{2+}$ and $\mathrm{CaS}: \mathrm{Eu}^{2+}$, respectively. Emission and excitation 


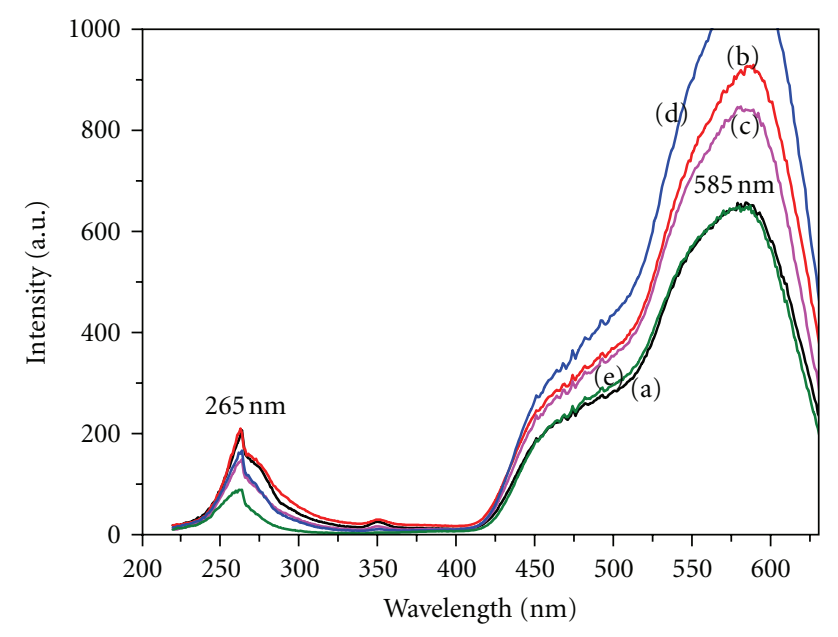

(a) $\mathrm{Eu}(0.004 \%)$
- (b) $\mathrm{Eu}(0.008 \%)$
(c) $\mathrm{Eu}(0.02 \%)$

Figure 1: Excitation spectrum of $\mathrm{CaS}: \mathrm{Eu}^{2+}$ at different $\mathrm{wt} \%$, monitored under $650 \mathrm{~nm}$ wavelength. Edited by Foxit Reader Copyright $(\mathcal{C}$ by Foxit Corporation, 2005-2009 For Evaluation Only.

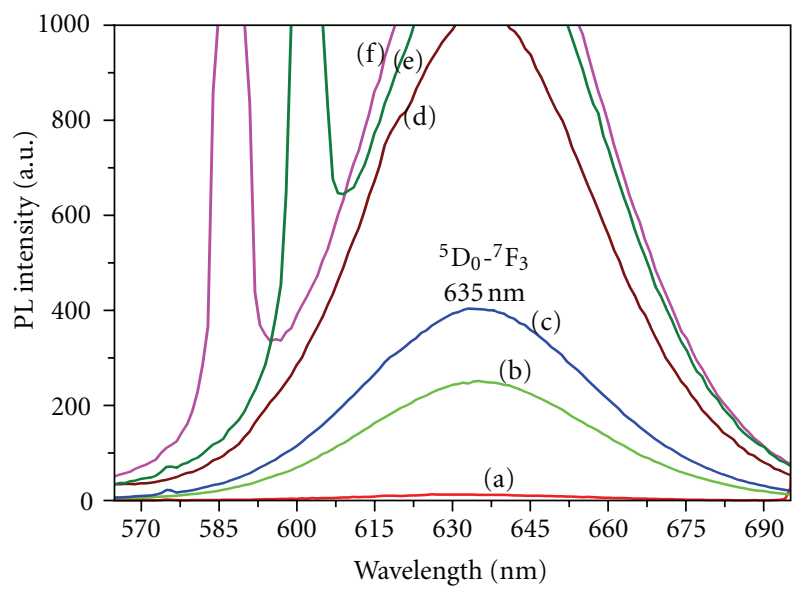
(a) Emission $\left(\lambda_{\mathrm{ex}}=350\right)$
(d) Emission $\left(\lambda_{\text {ex }}=540\right)$
(b) Emission $\left(\lambda_{\mathrm{ex}}=440\right)$
(e) Emission $\left(\lambda_{\mathrm{ex}}=585\right)$
(c) Emission $\left(\lambda_{\mathrm{ex}}=460\right)$
(f) Emission $\left(\lambda_{\mathrm{ex}}=600\right)$

Figure 2: Emission of CaS: $\mathrm{Eu}^{2+}(0.04 \mathrm{wt} \%)$ under different excitation wavelengths. Edited by Foxit Reader Copyright $(\mathcal{C}$ by Foxit Corporation, 2005-2009 For Evaluation Only.

spectra of the samples are measured with a Shimadzu RF $5301 \mathrm{PC}$ spectrofluorophotometer. Blue LED with a $460 \mathrm{~nm}$ emission is also used as an excitation source. LEDs are coated by the prepared phosphors.

\section{Results and Discussion}

3.1. Red and Orange Emissions of $\mathrm{CaS}: \mathrm{Eu}^{2+}$ and $\mathrm{SrS}: \mathrm{Eu}^{2+}$. $\mathrm{CaS}: \mathrm{Eu}^{2+}$ is a very efficient phosphor with a red emission that can be excited with visible light. Its emission is

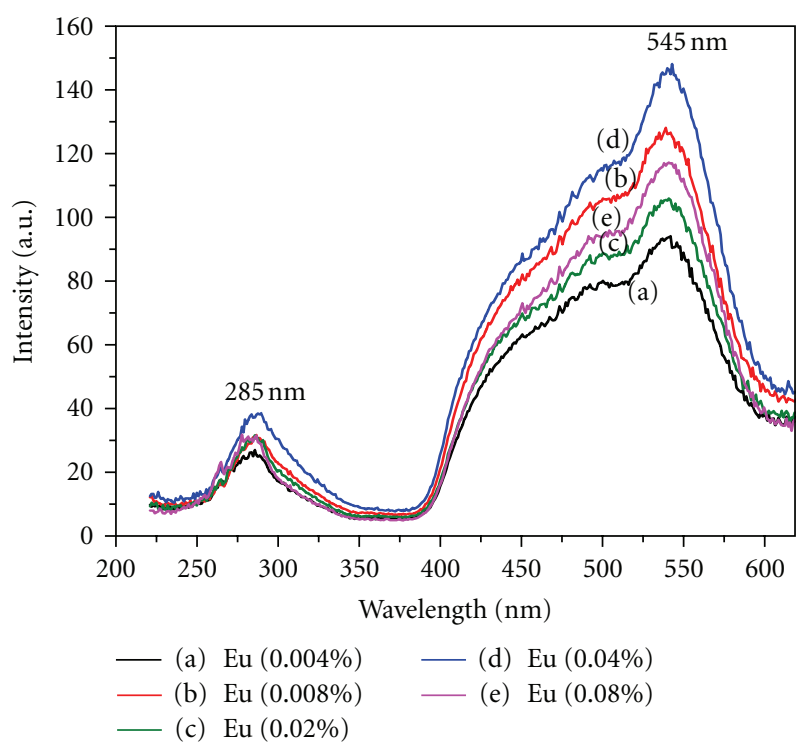

Figure 3: Excitation spectrum of $\mathrm{SrS}: \mathrm{Eu}^{2+}$ at different $\mathrm{wt} \%$, monitored under $650 \mathrm{~nm}$ wavelength. Edited by Foxit Reader Copyright $(\mathcal{C}$ by Foxit Corporation, 2005-2009 For Evaluation Only.

a single broad-band range from $550 \mathrm{~nm}$ to $700 \mathrm{~nm}$ peaked at $635 \mathrm{~nm}$ resulting from the $4 \mathrm{f}_{6} 5 \mathrm{~d}_{1}$ to $4 \mathrm{f}_{7}$ transition. Figure 1 shows the excitation spectrum of CaS:Eu at different $\mathrm{wt} \%$, which is monitored under $650 \mathrm{~nm}$ wavelength. The broad excitation bands of the $635 \mathrm{~nm}$ emission are found at $265 \mathrm{~nm}$ and $585 \mathrm{~nm}$, which can be attributed to the $\mathrm{e}_{\mathrm{g}}$ and $\mathrm{t}_{2 \mathrm{~g}}$ field splitting $5 \mathrm{~d}$ bands of $\mathrm{Eu}^{2+}$,respectively. Figure 2 shows the emission of $\mathrm{CaS}: \mathrm{Eu}^{2+}(0.04 \mathrm{wt} \%)$ studied under different excitation wavelengths $350,440,460,540,585$, and $600 \mathrm{~nm}$. The $635 \mathrm{~nm}$ emission is very high under $585 \mathrm{~nm}$ excitation. The emission intensity is high for $\mathrm{Eu}(0.04 \mathrm{wt} \%)$, concentration quenching is observed. There is no charge transfer transition observed from $\mathrm{Eu}^{2+}$ ground state to the host conduction band, implying that the $\mathrm{Eu}^{2+}$ ground state is close to the host valence band [10], or the lowest $5 \mathrm{~d}$ band overlaps with the host conduction band [11]. Bandgap of SrS is $4.32 \mathrm{eV}$ that is smaller compared to $\mathrm{CaS}(4.434 \mathrm{eV})$. Lattice constant of $\mathrm{SrS}$ is $6.019 \AA$ that is bigger than that of $\mathrm{CaS}$ $(5.697 \AA)$. The ligand field splitting of $5 \mathrm{~d}$ level of $\mathrm{Eu}^{2+}$ results in red shifts for both emission and excitation peaks from $\mathrm{CaS}$ host to $\mathrm{SrS}$ host. A single broad-band emission of $\mathrm{Eu}^{2+}$ in $\mathrm{SrS}$ is blue shifted to $600 \mathrm{~nm}$ as shown in Figure 4. The broadband excitation peaks of $5 \mathrm{~d}$ field splitting components $\mathrm{e}_{\mathrm{g}}$ and $t_{2 g}$ are found, respectively, to have a red shift to $285 \mathrm{~nm}$ and a blue shift to a region from $390 \mathrm{~nm}$ to $585 \mathrm{~nm}$ as shown in Figure 3. This indicates a weaker field splitting of the $\mathrm{Eu}^{2+}$ $5 \mathrm{~d}$ state due to a weaker ligand field generated by a larger lattice. SrS and CaS have similar lattice symmetry, making them easier to have a solid solution in order to adjust the positions of absorption and emission and to obtain better color rendering for white LED applications [12].

3.2. Orange and Red Emissions Excited by LEDs. CaS:Eu ${ }^{2+}$ and SrS: $\mathrm{Eu}^{2+}$ with absorption peaks at $440 \mathrm{~nm}$ and $460 \mathrm{~nm}$, 




$\begin{array}{ll}\text { (a) Emission under } 285 \mathrm{ex} & \text { (d) Emission under } 500 \mathrm{ex} \\ \text { (b) Emission under } 440 \mathrm{ex} & \text { (e) Emission under } 540 \mathrm{ex}\end{array}$

(c) Emission under $460 \mathrm{ex}$

Figure 4: Emission of SrS:Eu ${ }^{2+}(0.04 \mathrm{wt} \%)$ under different excitation wavelengths.

respectively, are of interest for blue LED applications. Upon excitation at $460 \mathrm{~nm}$ from the blue LED, these alkali earth sulfide phosphors emit strong orange and red light. Each of singly doped phosphors is individually blended into transparent adhesives and coated onto the blue LEDs. The resulting luminous efficiency of W-LED was found as high as 30 and $23.6 \mathrm{~lm} / \mathrm{W}$ under $20 \mathrm{~mA}$ driving current. The CIE coordinates of W-LED are $x=0.3395, y=0.3434$ and $x=0.3356, y=0.2832$ with Ra values are 84.3 and 85.8 , respectively.

\section{Conclusion}

The excitation and emission spectra of these phosphors show that all are broadband, which can be viewed as the typical emission of $\mathrm{Eu}^{2+}$ ascribed to the $4 \mathrm{f}-5 \mathrm{~d}$ transitions. Because of their broadband absorption in the region $400-630 \mathrm{~nm}$, these phosphors meet the application requirements for blue LED chips. The critical quenching concentration of $\mathrm{Eu}^{2+}$ in both phosphors is observed. Moreover, a white light LED was fabricated through the integration of a $460 \mathrm{~nm}$ chip. The results indicate that $\mathrm{CaS}: \mathrm{Eu}$ phosphor can be considered as the most promising candidate for the application in blue LED chip-based white-light LEDs.

\section{Acknowledgment}

The authors K. Suresh and Ch. Achyutha Rao are grateful for the support from the University Grants Commission (UGC) under Faculty Development Programme.

\section{References}

[1] S. Nakamura, "The roles of structural imperfections in InGaN-based blue light- emitting diodes and laser diodes," Science, vol. 281, no. 5379, pp. 956-961, 1998.
[2] S. Nakamura, "III-V nitride based light-emitting devices," Solid State Communications, vol. 102, no. 2-3, pp. 237-248, 1997.

[3] S. Nakamura, M. Senoh, N. Iwasa, and S. I. Nagahama, "Highpower InGaN single-quantum-well-structure blue and violet light-emitting diodes," Applied Physics Letters, vol. 67, p. 1868, 1995.

[4] P. Schlotter, J. Baur, C. Hielscher et al., "Fabrication and characterization of GaN/InGaN/AlGaN double heterostructure LEDs and their application in luminescence conversion LEDs," Materials Science and Engineering B, vol. 59, no. 1-3, pp. 390-394, 1999.

[5] M. S. Shur and A. Žukauskas, "Solid-state lighting: toward superior Illumination," Proceedings of the IEEE, vol. 93, no. 10, pp. 1691-1703, 2005.

[6] A. A. Bergh, "Blue laser diode (LD) and light emitting diode (LED) applications," Physica Status Solidi A, vol. 201, no. 12, pp. 2740-2754, 2004.

[7] R. MuellerMach, G. O. Mueller, M. R. Krames, and T. Trottier, "High-power phosphor-converted light-emitting diodes based on III-Nitrides," IEEE Journal of Selected Topics in Quantum Electronics, vol. 8, no. 2, pp. 339-345, 2002.

[8] S. H. M. Poort, W. P. Blokpoel, and G. Blasse, "Luminescence of $\mathrm{Eu}^{2+}$ in barium and strontium aluminate and gallate," Chemistry of Materials, vol. 7, no. 8, pp. 1547-1551, 1995.

[9] S. Narukawa and G. Fasol, The Blue Laser Diode: GaN Based Light Emitters and Lasers, Springer, Berlin, Germany, 1997.

[10] T. Matsuzawa, Y. Aoki, N. Takeuchi, and Y. J. Murayama, "A new long phosphorescent phosphor with high brightness, $\mathrm{SrAl}_{2} \mathrm{O}_{4}: \mathrm{Eu}^{2+}, \mathrm{Dy}^{3+}$," Journal of Electrochemical Society, vol. 143, no. 8, pp. 2670-2673, 1996.

[11] S. A. Basun, M. Raukas, U. Happek et al., "Off-resonant spectral hole burning in CaS:Eu by time-varying Coulomb fields," Physical Review B, vol. 56, no. 20, pp. 12992-12997, 1997.

[12] Y. Hu, W. Zhuang, H. Ye, S. Zhang, Y. Fang, and X. Huang, "Preparation and luminescent properties of $\left(\mathrm{Ca}_{1-x}, \mathrm{Sr}_{x}\right) \mathrm{S}: \mathrm{Eu}^{2+}$ red-emitting phosphor for white LED," Journal of Luminescence, vol. 111, no. 3, pp. 139-145, 2005. 

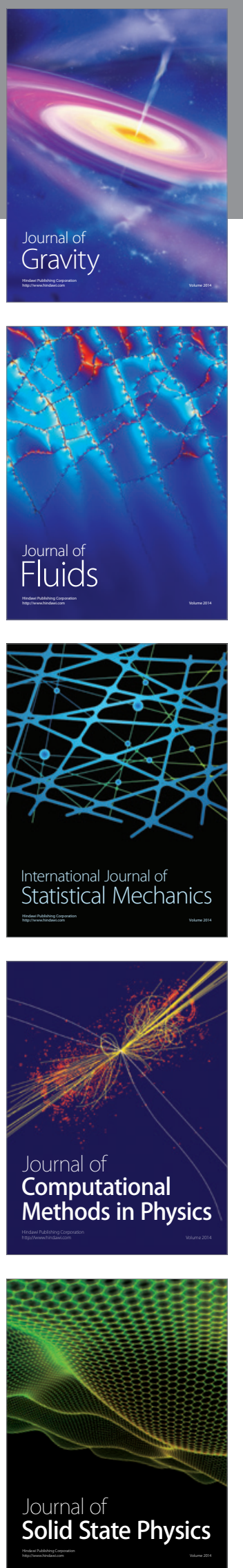
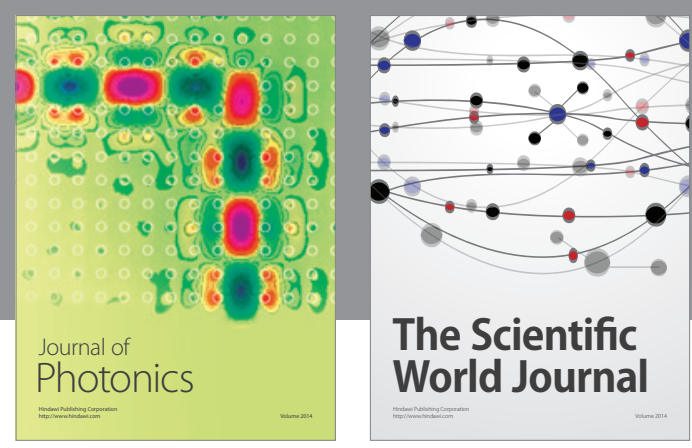

The Scientific World Journal



Submit your manuscripts at http://www.hindawi.com
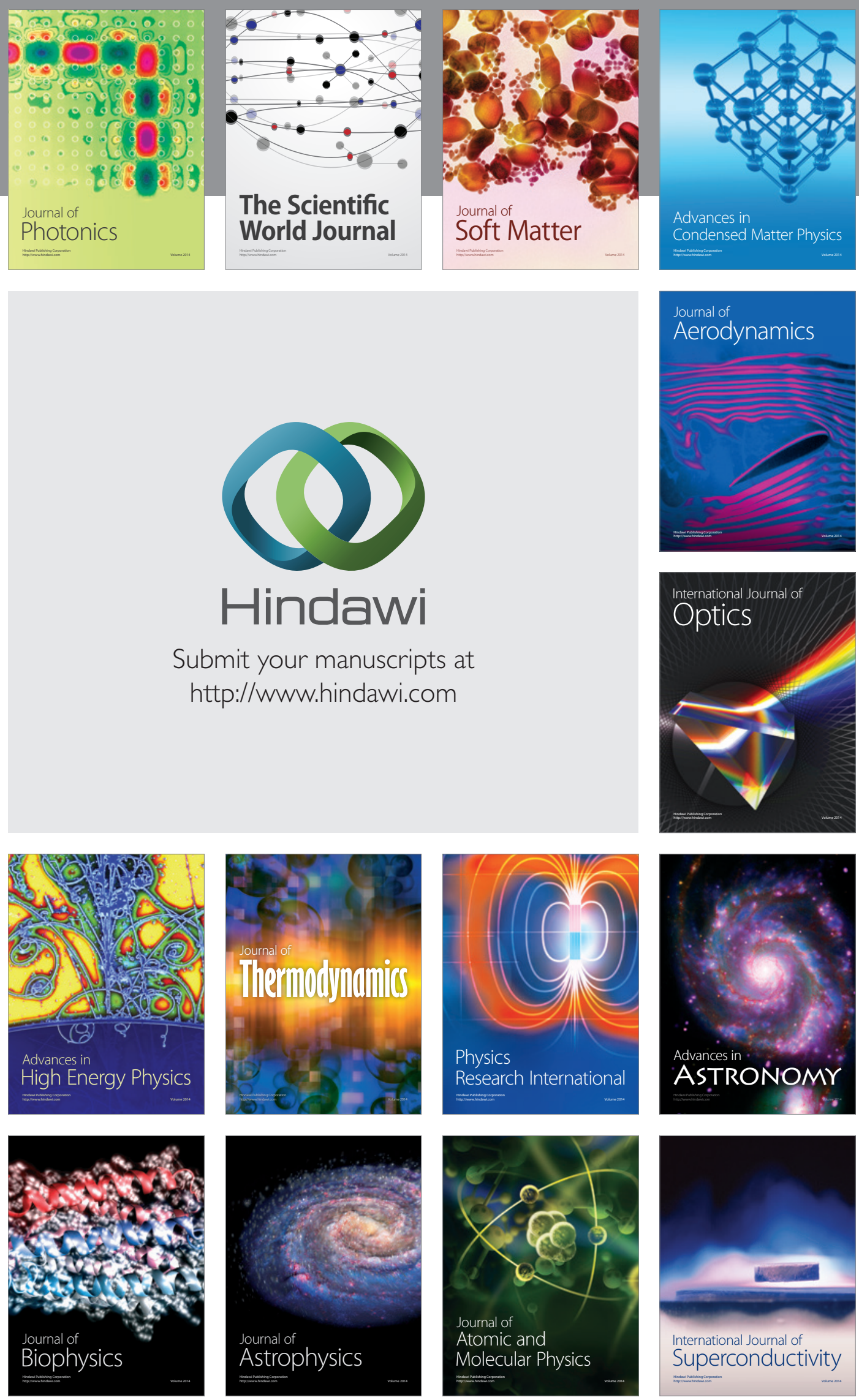
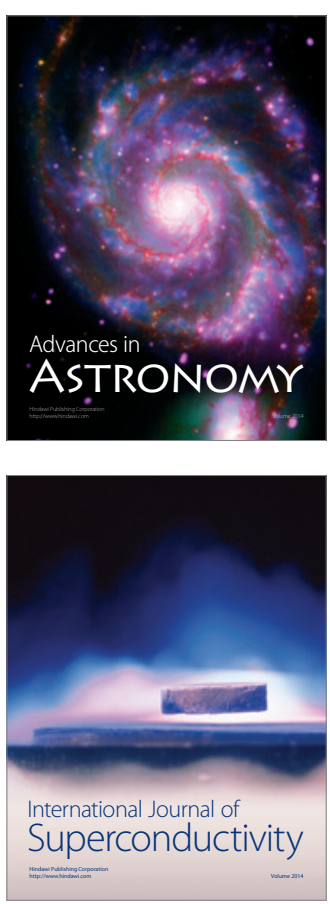